\title{
PEMBERIAN KOMPRES DINGIN TERHADAP PENURUNAN NYERI PADA PASIEN POST HEMOROIDEKTOMI DI RSUD SIMO BOYOLALI: STUDI KASUS
}

\author{
Tri Utami ${ }^{1}$, Ganik Sakitri ${ }^{2}$ \\ ${ }^{1,2}$ Akper Insan Husada Surakarta \\ *Email: ganiksakitri2312@gmail.com
}

\begin{abstract}
Abstrak
Latar belakang. Hemoroid merupakan pembesaran atau pelebaran vena hemoroidialis yang melalui kanal anus atau rectum yang disebabkan oleh peradangan pada usus yang ditandai dengan nyeri dan rasa tidak nyaman yang bermanifestasi perdarahan setelah buang air besar. Tahun 2014 jumlah penderita hemoroid di dunia diperkirakan 230 juta orang. Tahun 2013 jumlah penderita hemoroid di indonesia berkisar 5,7\% dari total 10 juta orang. Data kejadian hemoroid di RSUD Simo Boyolali menyatakan pada bulan januari terdapat 3 jiwa dilakukan hemoroidektomi setiap minggunya. Salah satu masalah keperawatan utama pasien post operasi hemoroid adalah nyeri akut.

Tujuan Penelitian. Tujuan penelitian untuk mengetahui pengaruh pemberian kompres dingin terhadap penurunan nyeri pada pasien post operasi hemoroid.

Metode penelitian. Penelitian ini menggunakan metode case study design. Penelitian ini dilakukan pada bulan Januari 2019. Subyek penelitian adalah 2 orang pasien post operasi hemoroid di ruang bedah bougenvil RSUD Simo Boyolali. Intervensi yang dilakukan adalah melakukan kompres dingin suhu $5-10^{\circ} \mathrm{C}$ selama $10-15$ menit. Tehnik pengumpulan data adalah wawancara, obseervasi, dokumentasi.

Hasil penelitian. Studi kasus menunjukan bahwa tingkat nyeri pasien setelah dilakukan kompres dingin mengalami penurunan.

Kesimpulan. Studi kasus pemberian kompres dingin berpengaruh terhadap penurunan nyeri pada pasien post hemoroidektomi.

Kata kunci: hemoroidektomi, kompres dingin, nyeri.
\end{abstract}

\begin{abstract}
Background. Hemorrhoids are enlargements or widening of the hemoroiddial vein through the anus or rectum canal caused by inflammation of the intestine characterized by pain and discomfort that manifests bleeding after defecation. In 2014 the number of hemorrhoid sufferers in the world is estimated at 230 milion people, in 2013 the number of hemorrhoid sufferers in indonesia ranged from $5.7 \%$ of the total 10 milion people.Data on hemorrhoidal event at simo boyolali General Hospital stated that in january there were 3 people having hemorrhoidectomy every week. One of the main problem of patients with postoperative hemorrhoid is acute pain.

Research purpose. The aim of the study was to determine the effect of giving cold compresses on the reduction of pain scale in postoperative hemorrhoid patients.

Research methods. This study uses a case study design method. This research was conducted on January 2019. Research subjects were 2 post hemorrhoidal surgery patients in the bougainvillea operating room of simo Boyolali General Hospital. The intervention was cold compresses temperature of 5- 10 $\mathrm{C}$ for 10-15 minutes. Data collection techniques are interviews, observation, documentation.

Research results. Case studies show that the patient's pain level after a cold compresses has decreasesd.
\end{abstract}


Conclusion. Case studies of giving cold compresses have an effect on reducing pain in postoperative hemorrhoid patients.

Keywords : hemorrhoid, cold compresses, pain.

\section{Pendahuluan}

Hemoroid adalah suatu pelebaran dari vena-vena didalam pleksus hemoroidialis (Muttaqin, 2011). Hemoroid adalah pelebaran pembuluh darah vena hemoroidialis dengan penonjolan membran mukosa yang melapisi daerah anus dan rektum (Nugroho, 2011).

Hemoroid merupakan gangguan umum yang dapat terjadi pada laki-laki maupun perempuan pada usia sekitar 20-50 tahun (Black \& Hawks, 2009). World Healt Organization (2014) menyatakan jumlah penderita hemoroid di dunia di perkirakan 230 juta orang. Di amerika serikat diperkirakan 10 juta jiwa mengalami hemoroid . prevelensi tersebut sekitar 4,4\% dilakukan pengobatan sedangkan yang dilakukan hemoroidektomi berjumlah $1,5 \%$.

Menurut data Kemenkes RI (2013), prevelensi hemoroid berkisar 5,7\% dari total 10 juta orang. Data kejadian hemoroid di RSUD Simo, Boyolali menyatakan pada bulan januari terdapat 3 jiwa dilakukan hemoroidektomi setiap minggunya. Pasien hemoroid akan mengalami tanda dan gejala meliputi perdarahan, nyeri adanya prolaps (benjolan) dan kadang merasa gatal-gatal di rektum. Gejala stadium awal pada hemoroid interna yaitu keluarnya darah yang berwarna merah terang dan tidak disertai nyeri pada akhir defekasi. Sedangkan gejala pada stadium akhir berupa prolaps yang menetap dan tidak bisa masuk lagi meskipun didorong secara manual (Syamsuhidayat \& Joong, 2004). Adapun komplikasi hemoroid yaitu perdarahan akut, perdarahan kronik dan terjadi inkarserasi prolaps. Hal ini dapat menyebabkan infeksi sampai sepsis dan gangren yang menyebabkan bau menyengat (Prace, 2005; Fiona \& Alexis, 2013).

Penatalaksanaan hemoroid dapat dilakukan secara bedah dan no bedah. Penanganan non bedah meliputi skleroterapi, Rubber Band Ligation (RBL), koagulasi bipolar, sinar inframerah (Lohsiriwat, 2012). Penatalaksanan bedah hemoroid adalah dengan hemoroidektomi. Hemoroidektomi adalah operasi pengangkatan hemoroid dengan cara eksisi yakni dengan mengangkat jaringan yang mengalamivarises (pelebaran) yang terjadi didaerah kanalis analis (Jacobs, 2014).

Nyeri post operasi disebabkan oleh adanya stimulus mekanik akibat kerusakan jaringan dariprosedur pembedahan yaitu luka (insisi), sehingga akan merangsang mediator-mediator zat kimia dari nyeri (Potter \& Perry, 2009). Prostaglandin, histamin, serotonin, bradikinin, asetil kolin, substansi $\mathrm{P}$, leukotrien merupakan zat-zat kimia. Zat- 
zat tersebut akan terinduksi reseptor nyeri dan disalurkan serabut A-\& dan serabut $\mathrm{C}$ ke neuroaksis dimana zat-zat ini dapat meningkatkan sensifitas nyeri (Smeltzer \& Bare, 2010). Post operasi membuat kuli terbuka dan terluka sehingga menstimulus impuls nyeri ke saraf sensori dan teraktivasi di transmisikan ke kornus posterior di korda spinalis. Saraf aferen akan menyampaikan persepsi nyeri ke otak (Brazz, 2014).

Penanganan nyeri non farmakologis yang dapat perawat lakukan diantaranya dengan memberikan stimulus kulit, relaksasi dan distraksi, masase, kompres dingin, kompres hangat, memberikan posisi yang nyaman, akupuntur, hidroterapi Transcutaneous Electrical Stimulation Nerve Stimulation (TENS) merupakan jenis stimulasi kulit (Demir, 2012). Kompres dingin mengurangi prostaglandin yang memperkuat reseptor nyeri, menghambat proses inflamasi dan merangsang pelepasan endorpin.

Kompres dingin mengurangi transmisi nyeri melalui serabut A-\& dan serabut C yang berdiameter kecil serta mengativasi serabut A-B yang berdiameter lebih cepat dan besar (Andarmoyo, 2013). Pengaruh kompres dingin dileher belakang atau tengkuk bertujuan untuk menghambat sensasi nyeri yang akan dihantarkan oleh impuls saraf ke sistem saraf pusat (otak).

Adanya tampon menimbulkan rasa mengganjal pada anus posthemoroidektomi (Langenbach, et al, 2013). Daily nutrition news (2016) menyatakan bahwa menempatkan air dingin di tengkuk pada titik feng fu selama 10-20 menit akan memberikan sensai yang luar biasa. Pada 30-40 detik pertama akan merasa dingin, selanjutnya akan memberikan rasa kehangatan. Hal ini karena dingin merangsang endorpin dilepaskan oleh otak dan spinal sehingga mengalir ke pembuluh darah yang dapat membuat rileks tubuh. Endorpin merupakan salah satu analgetik endogen yang bermanfaat bagi tubuh kita (Ossivop,et all, 2010).

\section{Metode Penelitian}

Penelitian ini menggunakan metode case study design yaitu merupakan rancangan penelitian yang mencakup pengkajian satu unit penelitian secara intensif misalnya satu pasien, karakteristik study kasus adalah subyek yang diteliti sedikit tetapi aspek yang diteliti banyak yang dimaksudkan untuk menilai pengaruh suatu tindakan terhadap tingkah laku atau menguji ada tidaknya pengaruh tindakan yang diberikan. Subyek dalam penelitian ini adalah 2 pasien post operasi hemoroid di ruang bougenvil RSUD Simo Boyolali. Instrumen yang digunakan adalah lembar NRS (Numeric Rating Scale) dimana intensitas nyeri diukur dalam skala 0-10, dengan nilai 0 menyatakan tidak nyeri dan nilai 10 menyatakan nyeri sangat berat. 
Tahapan perlakukan kompres dingin yang dilakukan pada pasien post operasi hemoroid meliputi pengkajian nyeri, kemudian dilakukan kompres dingin dengan suhu 5$10^{\circ} \mathrm{C}$. Pemberian kompres dingin dilakukan dalam waktu tiga hari sebanyak $3 \mathrm{x}$ sehari selama 10-15 menit.

\section{Hasil dan Pembahasan}

a. Karaktristik responden berdasarkan usia

Distribusi frekuensi responden berdasarkan usia di RSUD Simo Boyolali yang akan dijelaskan pada tabel dibawah ini :

Tabel 1 Karakteristik Responden Berdasarkan Usia

\begin{tabular}{lcc}
\hline \multicolumn{1}{c}{ Responden } & F & Usia \\
\hline Kompres air dingin & 1 & 42 tahun \\
Kompres air dingin & 1 & 20 tahun \\
Total & 2 & - \\
\hline Berdasarkan pada tabel 1 & didapatkan hasil dari 2 & orang responden usia 40
\end{tabular}
tahun dan 20 tahun.

b. Karakteristik responden berdasarkan jenis kelamin

Distribusi frekuensi responden berdasarkan jenis kelamin di RSUD Simo boyolali akan dijelaskan pada tabel di bawah ini :

Tabel 2 Karakteristik Responden Berdasarkan Jenis Kelamin

\begin{tabular}{llc}
\hline Responden & F & Jenis kelamin \\
\hline Kompres air dingin & 1 & Laki-laki \\
Kompres air dingin & 1 & perempuan \\
Total & 2 &
\end{tabular}

Berdasarkan pada tabel 2 didapatkan hasil responden berjenis kelamin lakilaki dan perempuan

c. Karakteristik responden berdasarkan pengalaman nyeri operasi sebelumnya

Distribusi frekuensi responden berdasarkan pengalaman nyeri operasi sebelumnya di RSUD Simo boyolali akan dijelaskan pada tabel dibawah ini :

Tabel 3 Karakteristik Responden Berdasarkan Pengalaman Nyeri Sebelumnya

\begin{tabular}{lcccc}
\hline Responden & F & $\begin{array}{c}\text { Pengalaman nyeri operasi } \\
\text { sebelumnya }\end{array}$ \\
\hline Kompres air dingin & & \multicolumn{2}{c}{ Tidak ada } \\
Kompres air dingin & 1 & ada \\
Total & 2 & didapatkan hasil satu responden memiliki
\end{tabular}
pengalaman nyeri operasi sebelumnya. 
d. Skala nyeri pasien post operasi hemoroid sebelum diberi kompres air dingin

Distribusi frekuensi responden berdasarkan skala nyeri pasien post operasi hemoroid sebelum diberi kompres air dingin di RSUD simo boyolali akan dijelaskan pada tabel di bawah ini :

Tabel 4 Skala Nyeri Sebelum Diberi Kompres Air Dingin

\begin{tabular}{lcc}
\hline Responden & F & Skala nyeri \\
\hline Kompres air dingin (L) & 1 & 5 \\
Kompres air dingin (P) & 1 & 6 \\
Total & 2 & \\
\hline \multicolumn{1}{c}{ Berdasarkan tabel } & 4 didapatkan hasil bahwa skala nyeri sebelum diberi
\end{tabular}

kompres air dingin responden laki-laki 5 dan responden perempuan 6 .

e. Skala nyeri pasien post operasi hemoroid sesudah diberi kompres air dingin selama 10-15 menit

Distribusi frekuensi responden berdasarkan skala nyeri pasien post operasi hemoroid sesudah diberi kompres air dingin di RSUD simo boyolali akan dijelaskan pada tabel di bawah ini :

Tabel 5 Skala Nyeri Sesudah Diberi Kompres Air Dingin

\begin{tabular}{lcc}
\hline Responden & F & Skala nyeri \\
\hline Kompres air dingin (L) & 1 & 2 \\
Kompres air dingin (P) & 1 & 3 \\
Total & 2 & \\
\hline \multicolumn{2}{c}{ Berdasarkan tabel 5 didapatkan hasil bahwa skala nyeri sesudah diberi }
\end{tabular}

kompres air dingin responden laki-laki 2 dan responden perempuan 3.

\section{Pembahasan}

\section{Karakteristik responden}

\section{Usia}

Pada penelitian ini usia responden berada pada rentan 20-42 tahun. Umur memiliki faktor resiko semakin bertambah usia semakin beresiko tinggi terkena hemoroid. Usia berkorelasi dengan pengalaman, pengalaman berkorelasi dengan pengetahuan, pemahaman dan pandangan terhadap suatu penyakit atau kejadian sehingga akan membentuk persepsi dan sikap (Lukman, 2011).

\section{Jenis kelamin}

Karakteristik jenis kelamin pada penelitian ini adalah laki-laki dan perempuan. Penelitian lain mengatakan bahwa angka kejadian hemoroid yang dilakukan hemoroidektomi antara laki-laki dan perempuan sama (Langenbach, 2013). Menurut asumsi peneliti karena terbatasnya jumlah responden dan tempat penelitian belum menggambarkan proporsi mayoritas berkaitan dengan jenis kelamin pada penderita hemoroid yang dilakukan hemoroidektomi. 


\section{Pengalaman nyeri operasi sebelumnya}

Karakteristik pengalaman nyeri sebelumnya pada penelitian ini adalah satu responden pernah mengalami nyeri karena tindakan pembedahan sebelumnya. Pasien yang memiliki pengalaman nyeri sebelumnya lebih cenderung mengantisipasi adanya nyeri yang lebih berat (Andarmoyo, 2013). Hal tersebut disebabkan proses pengendalian pusat neurokortek yang dipengaruhi pengalaman masa lalu. Riwayat nyeri operasi sebelumnya memiliki implikasi terhadap asesmen keperawatan.

Penurunan skala nyeri pasien post operasi hemoroid sebelum dan sesudah diberi kompres air dingin

Tabel 4 menunjukkan skala nyeri pasien post operasi hemoroid sebelum diberi terapi kompres air dingin pada responden laki-laki didapatkan skala 5 dan responden perempuan didapatkan skala 6 .

Tabel 5 menunjukan skala nyeri pasien post operasi hemoroid sesudah diberi terapi kompres air dingin selama tiga hari sebanyak 3x sehari selama 10-15 menit, pada responden laki-laki didapatkan skala 2 dan responden perempuan didapatkan skala 3 . Data yang telah didapatkan tersebut memiliki makna ada pengaruh pemberian kompres dingin terhadap penurunan skala nyeri pasien post operasi hemoroid.

Melakukan kompres dengan air dingin biasa pada bagian leher belakang selama 10-15 menit memiliki manfaat yang banyak salah satunya yaitu mengurangi rasa nyeri pada bagian tubuh . titik pada leher yang ditempelkan kantong berisi air dingin selama beberapa menit dapat menyebabkan penyembuhan pada nyeri, air dingin yang ditempelkan pada leher belakang ini bisa menekan titik panas dan menstimulasi energi .

Hal ini sejalan dengan penelitian Rohmani,dkk (2018) tentang penurunan nyeri dengan kompres dingin di leher belakang (tengkuk) pada pasien post hemoroidektomi terpasang tampon menunjukan mekanisme kompres dingin mampu menurunkan nyeri sebagaimana dijelaskan bahwa teori gate control dimana impuls dingin yang bersaing mencapai koreteks cerebri bersamaan impuls nyeri akan berefek pada distraksi kognitif dan menghambat persepsi nyeri.

Prinsip yang mendasari penurunan nyeri oleh kompres dingin bahwa kompres dingin bekerja dengan menstimulasi reseptor tidak nyeri, komores dingin dapat menurunkan prostaglandin yang memperkuat sensitifitas reseptor nyeri (Saputra,dkk, 2017).

Kompres dingin memberikan efek fisiologis yakni menurunkan respon inflamasi, menurunkan aliran darah dan mengurangi edema, mengurangi rasa nyeri lokal (Ayang $e t$ al, 2016). 
Kompres dingin merupakan suatu prosedur menempatkan suatu benda dingin pada tubuh bagian luar. Dampak fisiologisnya adalah vasokontriksi pada pembuluh darah, mengurangi rasa nyeri, dan menurunkan aktifitas ujung saraf pada otot. Penggunaan kompres dingin terbukti dapat menghilangkan nyeri, terapi dingin menimbulkan efek analgetik dengan memperlambat kecepatan hantaran saraf sehingga impuls nyeri yang mencapai otak lebih sedikit (Eva, 2013).

\section{Kesimpulan}

\section{Simpulan}

Ada pengaruh pemberian kompres dingin terhadap penurunan nyeri sedang menjadi nyeri ringan pada pasien post operasi hemoroid di ruang bougenvil RSUD Simo Boyolali.

\section{Saran}

Pemberian kompres dingin dapat dilakukan dengan sampel yang lebih banyak guna memenuhi metode penelitian quasy eksperimen dan diharapkan pada peneliti selanjutnya dapat mengganti media lain yang suhunya dapat stabil lebih lama.

\section{Daftar Pustaka}

Andarmoyo. S. 2013. Konsep dan Proses Keperawatan Nyeri. Yogyakarta: AR-RUZZ Media.

Ayang. et all. 2016. Pengaruh kompres dingin terhadap tingkat nyeri luka perianal pada ibu nifas di RSU Pku Muhammadiyah Bantul. http://lib.unisayogya.ac.id

Black. J.M., \& Hawks, J.H. 2009. Medical Surgical Nursing: Clinical Management for positive outcomes, Eight edition. Singapore: Sounders Elsiver http://jurnalpoltekkesjayapura.com/index.php/jktp

Demir. Y. 2012. Non-pharmacological therapies in pain management,Pain managementcurrent issues and opinions. Dr. Gabor Racz (Ed). ISBN: 978-953-307-8137.http://jurnalpoltekkesjayapura.com/index.php/jktp

Eva silviana rahmawati 2013. Pengaruh kompres dingin terhadap pengurangan nyeri luka perineum pada ibu nifas di BPS Siti Alfirdaus Kingking Kabupaten Tuban.

Fiona. H., \& Alexis, S. 2013. Assesment and treatment of patiens withHaemorrhoids. Nursing Standard.Vol.24, http://jurnalpoltekkesjayapura.com/index.php/jktp

Gebbenslaben, O., Hilger, Y.,\& Rohde, H. 2009. Etiology of Thombosed External Hemorrhoid: Result from a Prospective Cohort Study. The International Journal of Gastroenterology. http://jurnalpoltekkesjayapura.com/index.php/jktp

Jacobs. D. 2014. Hemorrhoids. Clinical practice. The New England Journal of Medicine. 371 , 944-51. DOI:10.1056/NEJMcp 1204188. 
http://jurnalpoltekkesjayapura.com/index.php/jktp

Langenbach. M.R,. Chondros, S., \& Sauerland, S. 2013. Tamponade dressing May be unnecessary after haemorroidectomy: a randomised controlled clinical trial: International Journal Colorectal Dis. 29,395-400. DOI 10.1007/s00384-0131800-z.http://jurnalpoltekkesjayapura.com/index.php/jktp

Lohsiriwat. V. 2012. Hemorroid: From Basic Pathophysiology to clinical Management. Word Journal of Gastroenterology. Mahidol University, Thailand. Vol.18.17, 2009-2012. DOI :10.3748/WJG.V18.I17.2012.

available at http://jurnalpoltekkesjayapura.com/index.php/jktp

Lukman, N. 2011. Asuhan Keperawatan Pada Klien Dengan Gangguan Sistem Muskuloskeletal. Jakarta : Selemba.

Muttaqin. Arif dan Kumala Sari. Gangguan Gastrointestinal AplikasiAsuhan Keperawatan Medikal Bedah. Jakarta: Salemba Medika, 2011.

Nugroho. Taufan. Asuhan Keperawatan Maternitas, Anak, Bedah, Penyakit Dalam. Yogyakarta: Nuha Medika, 2011.

Ossipov. M.H., Dussor, G.O., \& Porreca, F. 2010. Central modulation of pain. The Journal of Clinical Investigation. Vol. 120, 3779-3787.

http://jurnalpoltekkesjayapura.com/index.php/jktp

Potter. P.A., \& Perry, A.G. 2009. Fundamental of Nursing Fundamental Keperawatan Buku 1 Edisi 7. Jakarta: Salemba Medika.

Rohmani. dkk 2018. Penurunan nyeri dengan kompres dingin di leher belakang (tengkuk) pada pasien post hemoroidektomi terpasang tampon. http://jurnalpoltekkesjayapura.com/index.php/jktp

Saputra. dkk 2017. Pengaruh kompres dingin terhadap penurunan nyeri pada pasien post operasi di Rumah Saskit Islam Siti Khatidjah Palembang tahun 2017. http://jurnal.stiksitikhadijah/ac.id/index.php/multiscience/article/vies/27

Simadibrata, dkk. 2006. Buku Ajar Ilmu Penyakit Dalam. Penerbit Departemen Ilmu Penyakit Dalam Fakultas Kedokteran Univesitas Indonesia; Jakarta

Sjamsuhidayat \& Jong. 2004. Buku Ajar Ilmu Bedah edisi revisi. Jakarta: EGC.

Smiltzer \& Bare. 2010. Textbook Of Medical Surgical Nursing. Brunner \& Suddart. Twelfth Edition. Lippincot Company. 